\title{
Pertuzumab and trastuzumab: the rationale way to synergy
}

\author{
SANDRINE RICHARD ${ }^{1}$, FRÉDÉRIC SELLE ${ }^{1}$, JEAN-PIERRE LOTZ ${ }^{1,2}$, AHMED \\ KHALIL ${ }^{1}$, JOSEPH GLIGOROV ${ }^{1,2}$ and DANIELE G. SOARES ${ }^{1}$ \\ ${ }^{1}$ Medical Oncology Department, APREC (Alliance Pour la Recherche En Cancérologie), Tenon Hospital \\ (Hôpitaux Universitaires de l'Est-Parisien, AP-HP), rue de la Chine, 75020 Paris, France \\ ${ }^{2}$ Institut Universitaire de Cancérologie Université Pierre et Marie Curie (IUC-UPMC Univ \\ Paris 06), Sorbonne Universités, 4 place Jussieu, 75005 Paris, France
}

Manuscript received on March 13, 2015; accepted for publication on May 5, 2015

\begin{abstract}
It has now been 15 years since the HER2-targeted monoclonal antibody trastuzumab was introduced in clinical and revolutionized the treatment of HER2-positive breast cancer patients. Despite this achievement, most patients with HER2-positive metastatic breast cancer still show progression of their disease, highlighting the need for new therapies. The continuous interest in novel targeted agents led to the development of pertuzumab, the first in a new class of agents, the HER dimerization inhibitors. Pertuzumab is a novel recombinant humanized antibody directed against extracellular domain II of HER2 protein that is required for the heterodimerization of HER2 with other HER receptors, leading to the activation of downstream signalling pathways. Pertuzumab combined with trastuzumab plus docetaxel was approved for the first-line treatment of patients with HER2-positive metastatic breast cancer and is currently used as a standard of care in this indication. In the neoadjuvant setting, the drug was granted FDA-accelerated approval in 2013. Pertuzumab is also being evaluated in the adjuvant setting. The potential of pertuzumab relies in the dual complete blockade of the HER2/3 axis when administered with trastuzumab. This paper synthesizes preclinical and clinical data on pertuzumab and highlights the mechanisms underlying the synergistic activity of the combination pertuzumab-trastuzumab which are essentially due to their complementary mode of action.
\end{abstract}

Key words: breast cancer, dimerization, HER2/3, monoclonal antibody, pertuzumab, trastuzumab.

INTRODUCTION

The human epidermal growth factor receptor 2 (HER2, ErbB-2 or HER-2/neu) gene, which encodes the HER2 receptor tyrosine kinase, is amplified in about $20 \%$ of breast cancers (Ross and Fletcher 1998) and is associated with a poor prognosis and an aggressive phenotype (Slamon et al. 1987).

Correspondence to: Daniele Grazziotin-Soares

E-mail: daniele.grazziotin-soares@aphp.fr
By introducing trastuzumab (Herceptin) based therapy (Baselga et al. 1996) for the treatment of both, early (Slamon et al. 2011, Gianni et al. 2012) and metastatic HER2-positive breast cancer (Slamon et al. 2001), the prognosis of patients has substantially improved.

Trastuzumab works through multiple mechanisms to inhibit tumor growth, including inhibition of downstream signalling by blocking either HER2 homodimerization (Ghosh et al. 2011) or ligand- 
independent HER2/HER3 heterodimerization (Junttila et al. 2009). Trastuzumab also inhibits HER2 activation by inhibiting the cleavage of its extracellular domain, thus preventing the formation of the truncated and very active form of HER2, p95HER2 (Molina et al. 2001, Nahta and Esteva 2006). Finally, trastuzumab induces antibodydependent cell-mediated toxicity (Hudis 2007).

Despite its effectiveness in both adjuvant and metastatic settings, therapeutic resistance to trastuzumab remains an important clinical issue. Approximately, $15 \%$ of patients relapse after treatment (Kümler et al. 2014) because of acquired resistance (Pohlmann et al. 2009, Chung et al. 2013). Indeed, median time to progression remained less than one year when trastuzumab was combined with chemotherapy (Slamon et al. 2001, Esteva et al. 2002).

It is important to mention that tumor cell with acquired resistance to trastuzumab continues to depend on the HER2 oncogene. Indeed, gene amplification and RNA/protein overexpression are still present in trastuzumab-resistant HER2+ clones (Ritter et al. 2007).

The mechanisms underlying the frequent development of resistance to trastuzumab are only starting to be understood and are still under active investigation (Garrett and Arteaga 2011). Several of the proposed mechanisms of resistance to trastuzumab involve persistence or reactivation of the PI3K signalling through amplification of alternative tyrosine kinase receptor and/or mutations in the PI3K components (Rexer and Arteaga 2013). The formation of insulin-like growth factor-I receptor (IGF-IR)/HER-2 heterodimer may also contribute to trastuzumab resistance (Nahta et al. 2005). In particular, trastuzumab does not seem to be able to prevent ligand-activated HER2/HER3 or HER2/HER1 heterodimerization which could give tumor cells a way to escape from the inhibitory effects of trastuzumab (Ghosh et al. 2011).

The mechanism of HER2 signalling has been the focus of extensive research in order to identify additional targets therapies for patients with trastuzumab-resistant breast cancer. A number of agents targeting various downstream components of the pathways associated with HER2 signalling are currently under clinical investigation. These molecules include extracellular targeted therapies (monoclonal antibodies directed against HER family receptors), intracellular targeted therapies (tyrosine kinase inhibitors) and agents that target downstream effectors including members of either the mitogen-activated protein kinase (MAPK) or the phosphatidylinositol 3-kinase (PI3K) pathways. In addition to PI $3 \mathrm{~K} / \mathrm{AKT}$ modulators, targeted therapies directed at the Hsp-90 apoptotic pathway as well as factors modulating angiogenesis are also currently being developed (Rosen et al. 2010).

\section{THE EGFR FAMILY RECEPTORS}

HER2 is one of the four members of the human EGFR family, which also includes EGFR (HER1 or ErbB-1), HER3, and HER4 (Hudis 2007). The HER gene family is encoded by genes on different chromosomes and regulate normal breast growth and development. However, their deregulations leading to the activation of downstream pathways appear to be particularly important, not only for tumor development but also for treatment efficacy (Roskoski Jr 2004).

Each HER receptor shows an extracellular domain, a helical transmembrane segment, and an intracellular protein tyrosine kinase domain. The extracellular region of each HER receptor contains four domains (I-IV). Domains I, III and IV are involved in ligand binding. The domain II loop, the so called dimerization arm, promotes direct receptor-receptor interaction.

Most of the HER receptors have a ligand. For example, HER3 has a specific ligand, heregulin (HRG), but does not have any kinase activity. HER2 is unique since it does not have any known ligand (orphan receptor) but shows a tyrosine kinase activity (Kim et al. 1998). HER2 is activated 
through homo- or heterotypic interactions of its extracellular domain with that of other HER receptors (Arribas et al. 2011).

In the absence of ligand binding, HER 1 and HER3 exist in a tethered conformation in which intramolecular interaction between domains II and IV blocks the function of dimerization domain II. Ligand binding to HER receptors changes the tethered conformation into an extended conformation, which exposes domain II, allowing them to undergo dimerization (Hynes and Lane 2005, Gala and Chandarlapaty 2014, Burgess et al. 2014).

Interestingly, the structure of the HER2 extracellular region dramatically diverges from those of either HER1 or HER3. The HER2 extracellular region has indeed a fixed conformation and the domain II loop is exposed to interactions (Lemmon and Schlessinger 2010). This constitutive exposure of its dimerization arm might explain why HER2 is the favored partner for the other ligand-dependent HER (Graus-Porta et al. 1997, Yarden and Sliwkowski 2001, Badache and Hynes 2004). Moreover, the high level of HER2 present at the surface of HER-positive tumor cells facilitates a spontaneous formation of HER2 homodimers (Yarden and Sliwkowski 2001, Atalay et al. 2003).

The role of HER2 in heterodimers formation seems to be related to its capacity to act as a coreceptor, increasing the affinity of the ligand binding to the heterodimerized receptor complexes (Atalay et al. 2003, Graus-Porta et al. 1997).

The HER receptors dimerization and phosphorylation lead to the activation of intracellular signalling cascades including both the phosphatidylinositol triphosphate kinase (PI3K)/protein kinase $\mathrm{B}(\mathrm{Akt})$ and the mitogen-activated protein kinase (MAPK)/ERK pathways (Yarden and Sliwkowski 2001, Atalay et al. 2003, Park et al. 2008, Rosen et al. 2010). Ultimately, these signaling cascades lead to the expression of target genes that regulate various cellular processes influencing growth, proliferation, migration and survival (Yarden and Sliwkowski 2001) (Fig. 1).
Preclinical works have reported that the HER3-ligand binding HRG enhanced HER2/HER3 heterodimer formation. Indeed, HRG induces recruitment of HER3 to an HER2-Src, resulting in upregulation of tyrosine phosphorylation and kinase activation (Vadlamudi et al. 2003, Ghosh et al. 2011). In contrast to HER3/HER2 heterodimers, HER2 homodimers and HER2/EGFR heterodimers do not induce Src kinase phosphorylation and activation (Vadlamudi et al. 2003, Huang et al. 2010).

It has been suggested that the formation of the HER2-HER3 heterodimer has the strongest transforming capacity compared to the other HER homo- and heterodimers. Despite the absence of tyrosine kinase activity, HER3 has multiple PI3K docking sites on its cytoplasmic domain, which therefore render it a potent activator of the tyrosine kinase enzyme (Xia et al. 2004).

\section{NOVEL STRATEGY TO TARGET HER2: PERTUZUMAB}

Pertuzumab is a recombinant, humanized, monoclonal antibody that binds to the extracellular dimerization domain II of HER2 (located on the opposite side of the domain IV where trastuzumab binds). Pertuzumab inhibits heterodimerization of HER2 with EGFR, HER3, HER4 (Nahta et al. 2004, Agus et al. 2002, Metzger-Filho et al. 2013) and IGF-1R (Nahta et al. 2005), whereas trastuzumab is preferentially active against tumors driven by HER2 homodimers (Ghosh et al. 2011).

More specifically, pertuzumab prevents ligand-induced dimerization of HER2 with HER3, thus inhibiting the activation of downstream cell signalling pathways that are critical for the tumor growth (Agus et al. 2002, Cho et al. 2003, Yarden and Sliwkowski 2001, Harari and Yarden 2000).

Pertuzumab can inhibit tumor cell growth following HRG-induced HER2 heterodimerization (Ghosh et al. 2011). However, pertuzumab, in contrast to trastuzumab, is not capable of preventing the formation of the p95HER2 truncated form (Molina et al. 2001). 


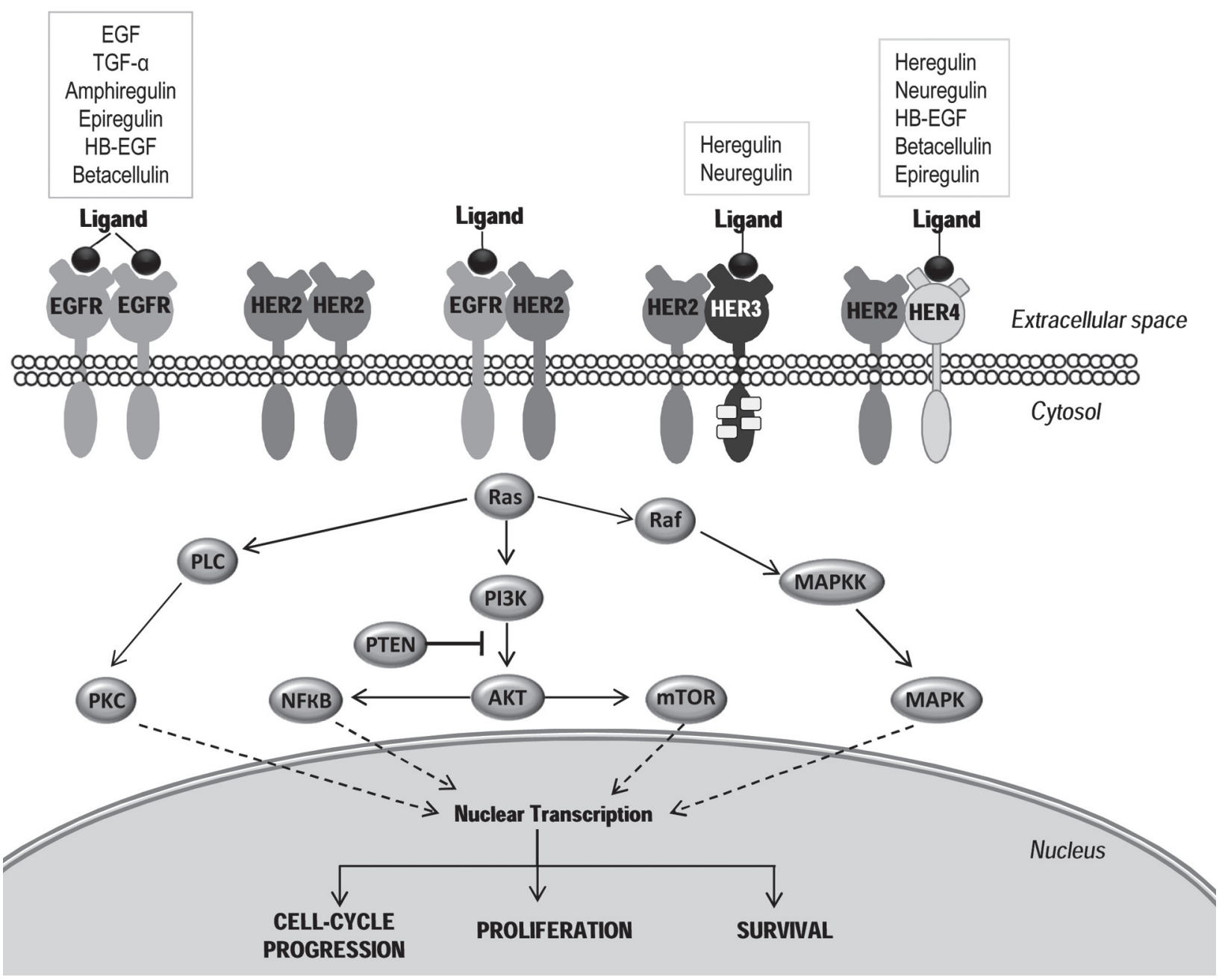

Figure 1 - HER receptors, their ligands and downstream signaling pathways activated following tyrosine kinase activity and receptor phosphorylation. The EGFR family consists of four different members: EGFR; human epidermal growth factor receptor (HER) 2; HER3; and HER4. Each HER receptor shows an extracellular domain, a helical transmembrane segment, and an intracellular protein tyrosine kinase domain. Upon ligand binding, these receptors can homodimerize or heterodimerize with each other to form several receptor combinations. The ligands of HER receptors are generated upon cleavage of transmembrane precursors and are characterized by an epidermal growth factor (EGF-like) domain composed of 3 disulfide-bonded intramolecular loops. HER2 is a unique member of the HER family which not bind any of the known ligands, but it is the preferred heterodimeric partner for other HER receptors. Ligand binding induces homo- or heterodimerization of the receptors, resulting in receptor phosphorylation on tyrosine residues within the cytoplasmic domains, which leads to activation of downstream signalling pathways. Note that the kinase domain of HER3 is catalytically inactive. The three best characterized signaling pathways induced through HER receptors are Ras-mitogen-activated protein kinase (Ras-MAPK), phosphatidylinositol 3 kinase(PI3K)-AKT (which is regulated by PTEN and involves other key effectors such as NFאB and mTOR), and phospholipase C-protein kinase C (PLC-PKC). As a result of these signaling pathways, different nuclear factors are recruited and modulate the transcription of different genes involved in cellcycle progression, proliferation and survival (Marmor et al. 2004, Fornaro et al. 2011).

For the above mentioned reasons, the different ways trastuzumab and pertuzumab work are likely to be complementary, and provide, when combined, a more complete blockade of HER2 downstream signaling than either agent alone (Fig. 2).

\section{PRECLINICAL DATA ON PERTUZUMAB}

In vivo preclinical studies showed that pertuzumab is active against various tumor types, including breast (Agus et al. 2002), ovary (Mullen et al. 
TUMOR SENSITIVITY

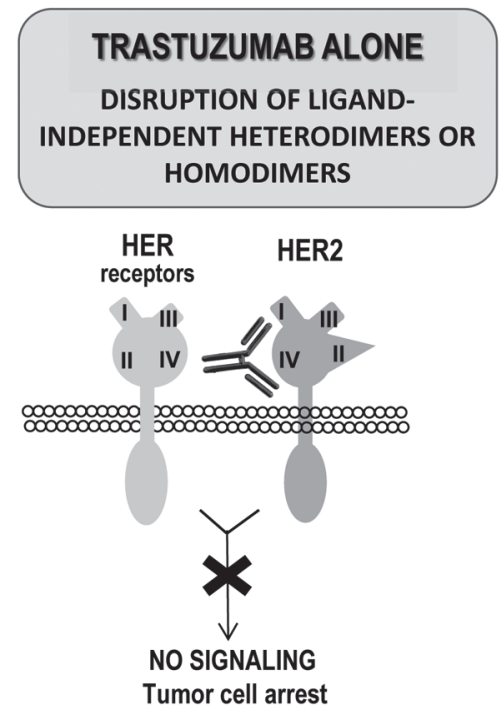

TUMOR RESISTANCE

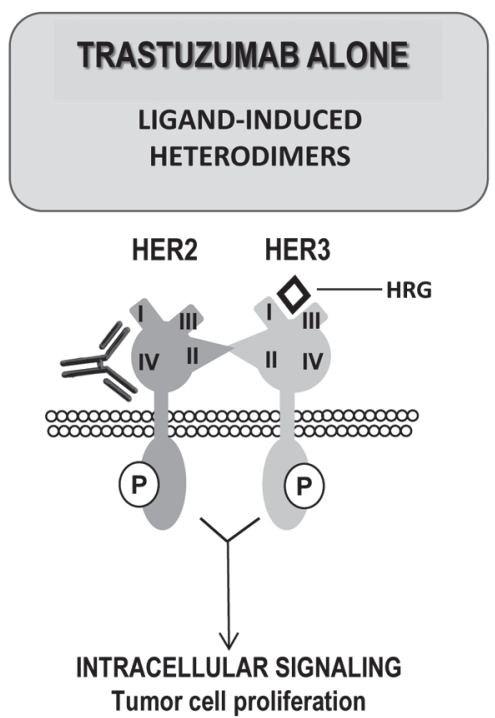

OVERCOMING RESISTANCE

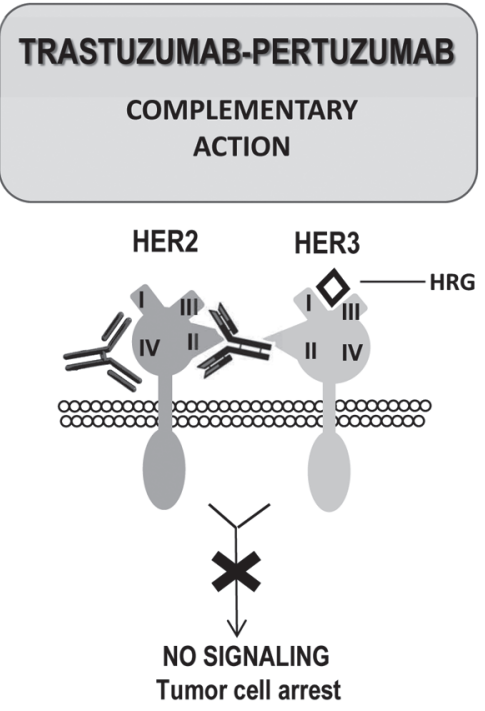

Figure 2 - The complementary mechanisms of pertuzumab and trastuzumab. (Left) HER2 receptors on the surface of the HER2-expressing breast cancer cells can dimerize with themselves or with other HER receptors in a ligand-dependent or independent manner, thus activating downstream signalling pathways promoting tumor cell proliferation, survival and invasion. Trastuzumab that binds to the domain IV of HER2, prevents the constitutive activation of HER2 by blocking its ligand-independent dimerization, induces its internalization and degradation, and stimulates the immune system to recognize and eliminate HER2overexpressing cells. (Middle) However, trastuzumab does not prevent the ligand-induced heterodimerization of the receptor with HER3. Following the heregulin (HRG) binding to HER3, a switch from the closed to the open state is induced, exposing the domain II dimerization arm to allow the formation of a HER2/HER3 heterodimer and intracellular signaling. (Right) Adding pertuzumab to trastuzumab promotes binding of pertuzumab to HER2 domain II and prevents HRG-mediated HER2/HER3 dimerization and signalling.

2007), non-small cell lung carcinoma (Sakai et al. 2007), prostate (Agus et al. 2002, Mendoza et al. 2002) and colon cancer (Pohl et al. 2009).

The resolution of the 3D structure of HER2 bound to pertuzumab (Franklin et al. 2004) provided important information regarding the role played by the different domains of the receptor for its activity in the context of either its overexpression or its ligand-induced activation.

The ability of pertuzumab to inhibit in vitro tumor cell growth by blocking HER2/HER3 heterodimerization and its ligand-induced activation is a unique trait which is not shared by trastuzumab (Lee-Hoeflich et al. 2008). The essential role of HER3 in tumor progression and drug resistance in HER2-dependent cells has previously been suggested. When both BT474MI and MCF-7 breast cancer cell lines were treated with heregulin and either pertuzumab or trastuzumab, pertuzumab was more efficient in disrupting ligand-mediated HER2/ HER3 complex formation and in blocking the appearance of a HRG-dependent phosphorylation signal of HER2 (Agus et al. 2002).

More recently, other works showed that inhibition of HER 2 phosphorylation by tyrosine kinase inhibitors (TKIs) targeting EGFR and HER2 in HER2-positive breast cancer cells, lead to feedback upregulation of activated HER3, thus limiting the inhibitory effect of HER TKIs (Sergina et al. 2007, Amin et al. 2010). Indeed, RNAi knockdown of HER3 or treatment with the HER3 neutralizing antibody AMG-888, sensitized 
HER2-positive cells to lapatinib-induced apoptosis (Garrett et al. 2011).

In agreement, the combination of pertuzumab with trastuzumab showed a synergistic effect when compared to pertuzumab single therapy in vitro on HER2-overexpressing BT474 breast cancer cell lines (Nahta et al. 2004). The combination of the two antibodies reduced by $60 \%$ the cell survival at doses for which individual drugs did not affect it. These data were confirmed in vivo in HER2positive breast and non-small cell lung cancer xenografts where the combination of trastuzumab and pertuzumab strongly enhanced the antitumor effect of both compounds and induced tumor regression in both xenograft models (Scheuer et al. 2009).

The enhanced efficacy of pertuzumab based combination was also observed when tumor progression occurred during the course of trastuzumab monotherapy (Scheuer et al. 2009). Here, the authors treated mice bearing KPL4 (a human cell line isolated from the malignant pleural effusion of a breast cancer patient with an inflammatory skin metastasis; Kurebayashi et al. 1999) tumor xenografts with trastuzumab until tumor mass started to progress again (day 35). At that point, the authors treated mice with either trastuzumab alone or trastuzumab combined to pertuzumab. The combination of the two antibodies was able to inhibit tumor growth and even reduce tumor mass for an additional 45 days.

Finally, it has been shown that both trastuzumab and pertuzumab induce the activation of the antibody-dependent cellular toxicity (ADCC) pathway, which is part of their antitumor activity (Scheuer et al. 2009, Mamidi et al. 2013). Indeed, through an in vitro ADCC assay, Scheuer and colleagues showed that both trastuzumab and pertuzumab applied as a single agent effectively activated ADCC with equal potency. However, there was no increase in ADCC efficiency when both agents were combined.

\section{CLINICAL STUDIES}

A single-arm phase II study evaluated pertuzumab in patients who had received up to 3 trastuzumabcontaining regimens and found a $24 \%$ positive response rate with $50 \%$ of patients demonstrating stable disease. This study suggested a role of pertuzumab in treating trastuzumab-resistant HER2 breast cancer (Baselga et al. 2010).

Although pertuzumab alone seemed to have antitumor activity, the combination of pertuzumab with trastuzumab was shown to be more efficient than pertuzumab monotherapy (Cortés et al. 2012). In this trial, pertuzumab was given as monotherapy to patients with advanced HER2 positive breast cancer whose disease had progressed during prior trastuzumab-based therapy. When progressive disease or unacceptable toxicity was observed, trastuzumab was reintroduced and patients received a combination of pertuzumab and trastuzumab. Progression-free survival was increased in the combination arm compared to the pertuzumab monotherapy arm (17.4 v 7.1 weeks, respectively). Importantly, the treatment was well tolerated with minimal cardiac dysfunction.

The efficacy of adding pertuzumab to trastuzumab plus docetaxel for the first-line treatment of HER2-positive metastatic breast cancer was demonstrated in a randomized, double-blind, multinational, phase III CLEOPATRA (Clinical Evaluation of Pertuzumab and Trastuzumab) trial (Baselga et al.2012). Patients with metastatic HER2positive breast cancer were randomly assigned to receive either pertuzumab by intravenous infusion (840 mg initial dose, $420 \mathrm{mg}$ every 3 weeks thereafter) or matched placebo as an add-on to the standard-of-care trastuzumab $(8 \mathrm{mg} / \mathrm{Kg}$ initial i.v. dose, $6 \mathrm{mg} / \mathrm{Kg}$ i.v. every 3 weeks thereafter) and docetaxel $(75 \mathrm{mg} / \mathrm{m} 2$ i.v. every 3 weeks for at least 6 cycles, with the option of dose escalation to 100 $\mathrm{mg} / \mathrm{m} 2$ ) (Fig. 3). A prolongation of progressionfree survival (PFS) in the pertuzumab arm (18.5 vs 


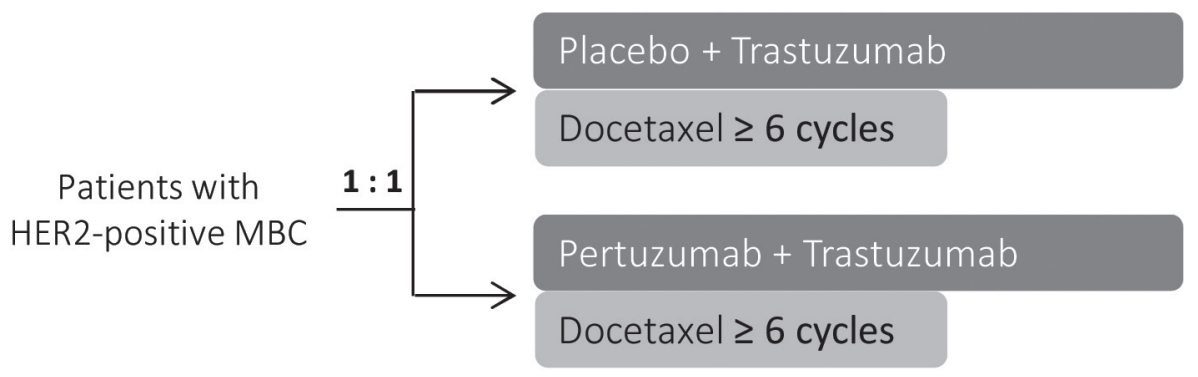

Figure 3 - The CLEOPATRA study design. The trial evaluated the efficacy of adding pertuzumab to trastuzumab plus docetaxel for the first-line treatment of HER2-positive metastatic breast cancer. MBC: metastatic breast cancer. Pertuzumab dosing: $840 \mathrm{mg}$ loading dose over $60 \mathrm{~min}$; $420 \mathrm{mg}$ over 30-60 min for subsequent infusions. Trastuzumab dosing: 8 $\mathrm{mg} / \mathrm{kg}$ loading dose over $90 \mathrm{~min} ; 6 \mathrm{mg} / \mathrm{kg}$ over 30-90 min for subsequent infusions.

12.4 months, $\mathrm{p}<.001$ ) with an objective response rate of $69.3 \%$ in the control arm compared with $80.2 \%$ in the pertuzumab arm was observed. Follow-up data at a median of 50 months showed a significant improvement of the overall survival (OS) with pertuzumab, trastuzumab, and docetaxel in patients with HER2-positive metastatic breast cancer, compared to patients receiving placebo, trastuzumab, and docetaxel (Swain et al. 2013).

On the basis of this clinical trial, pertuzumab has been approved by the U. S. Food and Drug Administration for use in combination with trastuzumab and docetaxel for the treatment of patients with HER2-positive metastatic breast cancer who have not received prior anti-HER2 therapy or chemotherapy for metastatic disease.

The positive results of the CLEOPATRA clinical trial are even more encouraging with respect to ongoing investigations on pertuzumab and trastuzumab in combination with a taxane. One example is the PERUSE trial (ClinicalTrials.gov Identifier NCT01572038), evaluating pertuzumab and trastuzumab in combination with paclitaxel, docetaxel, or nab-paclitaxel (Abraxane) with the aim to clarify whether one taxane is more appropriate than the other in the first line setting for HER 2 positive advanced breast cancer.

In the first line setting, however, the combination of pertuzumab, trastuzumab with ado- trastuzumab emtansine (an antibody-drug conjugate consisting of the monoclonal antibody trastuzumab linked to the cytotoxic agent DM1) may be preferable. In that regard, the ongoing trial MARIANNE (ClinicalTrials.gov Identifier NCT01120184) has the potential to change first-line therapy for HER2 positive metastatic breast cancer. Even if both treatments are equally efficacious, the toxicity with ado-trastuzumab is minimal. T-DM1 is a novel antibody-drug conjugate incorporating the trastuzumab with the cytotoxic activity of the microtubule-inhibitory agent DM1 (a derivative of maytansine). T-DM1 has been shown to significantly prolong progression-free and overall survival with less toxicity than lapatinib plus capecitabine in patients with HER2-positive advanced breast cancer previously treated with trastuzumab and a taxane (Verma et al. 2012).

Based on exciting results of trials which evaluated pertuzumab in the neoadjuvant setting, the drug was granted FDA-accelerated approval in 2013. In this setting, pathological response rates of the combination of pertuzumab or trastuzumab, or both, with docetaxel and the combination of pertuzumab and trastuzumab without chemotherapy were evaluated in the NeoSphere trial. Patients with locally advanced inflammatory or early breast cancer were treated and a significant improvement in pathological complete response (pCR) was 
observed in the group of patients given pertuzumab and trastuzumab plus docetaxel compared with those given trastuzumab plus docetaxel (Gianni et al. 2012). Interestingly, in patients treated with pertuzumab, trastuzumab plus docetaxel, the pCR rate was higher in patients with estrogen receptor (ER)-negative tumors (63.2\%) compared with those with ER+ tumors (27.3\%) (Gianni et al. 2012).

In the TRYPHAENA (Trastuzumab Plus Pertuzumab in Neoadjuvant HER2-Positive Breast Cancer) trial, patients with HER2+ tumors were randomized in three arms to receive six neoadjuvant cycles q3w (Arm A: 5-fluorouracil, epirubicin, cyclophosphamide [FEC] followed by docetaxel $[\mathrm{T}]$; with trastuzumab $[\mathrm{H}]$ and pertuzumab $[\mathrm{P}]$ given concurrently throughout $[\mathrm{FEC}+\mathrm{H}+\mathrm{P} \times 3$ $\rightarrow \mathrm{T}+\mathrm{H}+\mathrm{P}$ x 3]; Arm B: FEC followed by $\mathrm{T}+$ $\mathrm{H}+\mathrm{P}[$ FEC x $3 \rightarrow \mathrm{T}+\mathrm{H}+\mathrm{P} \times 3]$; or Arm C: $\mathrm{T}$, carboplatin; $\mathrm{H}$ with $\mathrm{P}[\mathrm{TCH}+\mathrm{P} \times 6]$. Following neoadjuvant therapy, patients underwent surgery and continued trastuzumab to complete 1 year of treatment (Fig. 4). The primary end-point was cardiac safety. All grades of symptomatic left ventricular systolic dysfunction (LVSD) were low across all 3 study arms: $5.6 \%, 4.0 \%$, and $2.6 \%$ in Arms A, B, and C, respectively. Grade 3 or higher LVSD was observed in $2.7 \%$ of patients in Arm A but not in Arms B and C. In conclusion, the combination of pertuzumab with trastuzumab and the standard chemotherapy resulted in low rates of symptomatic LVSD (Schneeweiss et al. 2013).

The combination of pertuzumab and trastuzumab is also under investigation in the adjuvant setting. The APHINITY trial (Adjuvant Pertuzumab and Herceptin in Initial Teraphy of breast cancer; ClinicalTrials.gov Identifier NCT01358877) is a placebo-controlled study in patients with HER2positive primary breast cancer who have had an excision of their tumor. Patients were randomized in two arms: (1) the investigational arm with a course of adjuvant chemotherapy consisting of a taxane-based regime (anthracycline-taxane or taxane-platin) and trastuzumab and pertuzumab for 1 year; (2) the comparator arm which consisted in the same adjuvant chemotherapy with trastuzumab and placebo for 1 year. The primary objective was to compare invasive disease-free survival between both treatment arms.

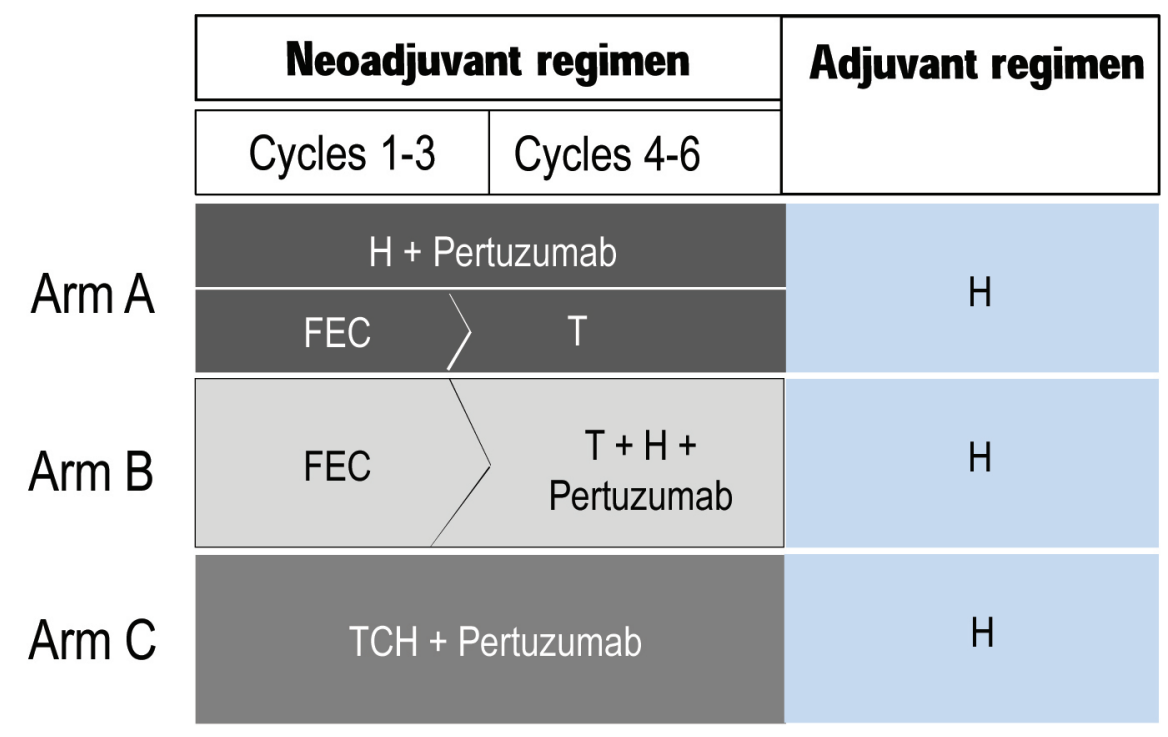

Figure 4 - The TRYPHAENA study design. The trial evaluated trastuzumab plus pertuzumab in neoadjuvant HER2-positive breast cancer. H: Trastuzumab; FEC: 5-fluorouracil, epirubicin, cyclophosphamide; T: docetaxel; TCH = docetaxel, carboplatin, and trastuzumab. 


\section{CONCLUSIONS}

The introduction of trastuzumab in the treatment of HER2-positive metastatic breast cancer patients favorably changed the natural history of this disease. However, despite this major advance, HER2positive metastatic breast cancer will eventually progress in most patients. One of the mechanisms responsible for the development of resistance to trastuzumab is the heterodimerization of HER2 with other HER receptors which may redundantly trigger cell proliferation signals.

A few years ago, one might have asked why we should combine two therapeutic antibodies targeting the same receptor. Today, in view of the mechanistic differences that have been identified through numerous preclinical works between trastuzumab and pertuzumab, this therapeutic approach should be encouraged. Pertuzumab, which could be considered as a prototype of HER2 dimerization inhibitor, shows mechanistic advantages that distinguish it from trastuzumab, in particular in regards to HER2 heterodimerization. However, one might consider that trastuzumab also shows mechanistic advantages over pertuzumab in regards to its ability to prevent the formation of the p95HER2 truncated form of HER2, thus highlighting their functional complementarity. This particularity is likely to play an important role on the demonstrated synergistic effect when both compounds are combined.

The approval of pertuzumab marked the first licensed dual anti-HER2 regimen for treatment of breast cancer and is likely to represent a major advance in the treatment of this pathology, comparable to the approval in 1998 of trastuzumab.

The clinical benefit of dual treatment with HER2-targeted antibodies with complementary mechanism of growth inhibition should also encourage further research in this field and open new therapeutic strategies. Consequently, numerous molecules are currently being developed. For example, LJM716 is a novel monoclonal antibody that is capable of neutralizing either ligand-dependent or independent HER3 signalling by locking HER3 in its inactive conformation. LJM716 is a potent inhibitor of both HER3/ AKT phosphorylation and proliferation in HER2expressing cancer cells and has displayed single agent efficacy in tumor xenograft models (Garner et al. 2013).

The development of a bispecific anti-HER2 antibody using both trastuzumab and pertuzumab is another example. This bispecific antibody (named TPL) retained the full binding activities of both parental antibodies, and exhibited pharmacokinetic properties similar to those of a conventional IgG molecule. TPL showed superior HER2 heterodimerization-blocking activity over the combination of both parental monoclonal antibodies. The unique potential of TPL to overcome trastuzumab resistance should be considered as a promising treatment in the clinic (Li et al. 2013).

Despite these recent advances, there are still a number of issues to be addressed. In particular, the identification of biomarkers is needed to identify patients more likely to respond, and to avoid treating patients likely to experience a worse outcome compared to the standard of care.

To date, and despite multiple researches in this area, the only robust biomarker allowing the prediction of response to HER2-targeted therapies is HER2 itself. Currently, HER2 status is determined by measurement of HER2 receptor protein and/or erbB2 gene amplification by immunohistochemistry or fluorescence in situ hybridization (FISH) (Singer et al. 2008). While the negative predictive value of these assays for predicting the absence of benefit from trastuzumab-based therapy is high, their positive predictive value remains insufficient. The clinical benefit and response rates appear to depend on the intensity of HER 2 overexpression $(2+$ or $3+$ ) with response rates of $35 \%$ in grade $3+$ expressors compared to only minimal benefit in $2+$ positives (Vogel et al. 2002). 
Results of biomarker analysis in the CLEOPATRA (Baselga et al. 2014) trial were consistent with those with smaller TRYPHAENA and NeoSphere of neoadjuvant trastuzumab plus pertuzumab in patients with HER2 positive early breast cancer, where the primary efficacy endpoint was pCR (Schneeweiss et al. 2012, Gianni et al. 2011). The PI3KCA status identified a subpopulation of patients with HER2-positive disease with poor prognosis when treated with anti-HER2 antibodies. Based on the findings of CLEOPATRA trial, clinical trials of HER2-targeted molecules in combination with PI3K pathway targeted agents may therefore be justified.

The identification of biomarkers is thus, urgently required in order to enable a better care of patients. Also, the medical staff would be able to adapt the treatment on the basis of the molecular features of the tumors and anticipate their modifications during the course of tumor progression. The understanding of the underlying mechanisms of either intrinsic or acquired resistance to HER2-targeting antibodies is also necessary, to define new therapeutic strategies and identify new targets. The ongoing development and success of these novel approaches rely, more than ever, on translational collaborations between basic scientists, preclinical researchers and clinicians.

\section{RESUMO}

Tem se passado 15 anos desde que o anticorpo monoclonal trastuzumab, direcionado contra a proteina HER2, foi introduzido na clinica e revolucionou o tratamento de pacientes com câncer de mama HER2positivo. Apesar disto, a maioria das pacientes com câncer de mama metastático e HER2-positivo ainda mostram progressão da doença, destacando a necessidade de desenvolver novas terapias. O interesse contínuo em novas moléculas alvo levou ao desenvolvimento do pertuzumab, o primeiro agente de uma nova classe, os inibidores da dimerização de HER. Pertuzumab é um novo anticorpo humanizado recombinante dirigido contra o domínio II extracelular da proteína HER2 que é necessário para a heterodimerização de HER2 com outros receptores HER, o que conduz à ativação de vias de sinalização intracelular. O pertuzumab combinado com trastuzumab e docetaxel foi aprovado como terapia de primeira linha para pacientes com câncer de mama metastático HER2-positivo e é atualmente indicado como padrão de tratamento para estas pacientes. Como terapia neoadjuvante, o medicamento recebeu aprovação do FDA em 2013. Além disso, o pertuzumab também está sendo avaliado como terapia adjuvante. O potencial do pertuzumab se baseia no bloqueio completo do eixo HER2/3 quando administrado em associação com o trastuzumab. Este artigo sintetiza dados pré-clínicos e clínicos do pertuzumab e destaca os mecanismos de ação complementares que explicam a atividade sinérgica da combinação pertuzumab-trastuzumab.

Palavras-chave: câncer de mama, dimerização, HER2/3, anticorpo monoclonal, pertuzumab, trastuzumab.

\section{REFERENCES}

AGUS DB ET AL. 2002. Targeting ligand-activated ErbB2 signaling inhibits breast and prostate tumor growth. Cancer Cell 2(2): 127-137.

AMin DN, SERgina N, AHuja D, MCMAHon M, BLAir JA, WANG D, HANN B, KOCH KM, SHOKAT KM AND MOASSER MM. 2010. Resiliency and vulnerability in the HER2-HER3 tumorigenic driver. Sci Transl Med 2(16): 16 ra7.

Arribas J, Baselga J, Pedersen K AND PARrA-PAlaU JL. 2011. p95HER2 and breast cancer. Cancer Res 71(5): 1515-1519.

Atalay G, CARdoso F, AwAdA A AND PiCCART MJ. 2003. Novel therapeutic strategies targeting the epidermal growth factor receptor (EGFR) family and its downstream effectors in breast cancer. Ann Oncol 14(9): 1346-1363.

BADACHE A AND HYNES NE. 2004. A new therapeutic antibody masks ErbB2 to its partners. Cancer Cell 5(4): 299-301.

Baselga J, Cortés J, IM SA, Clark E, Ross G, KIERMAIER A AND SWAIN SM. 2014. Biomarker analyses in CLEOPATRA: a phase III, placebo-controlled study of pertuzumab in human epidermal growth factor receptor 2-positive, first-line metastatic breast cancer. J Clin Oncol 32(33): 3753-3761.

BASELGA J ET AL. 2012. Pertuzumab plus trastuzumab plus docetaxel for metastatic breast cancer. N Engl J Med 366(2): 109-119.

BASELGA J ET AL. 2010. Phase II trial of pertuzumab and trastuzumab in patients with human epidermal growth factor receptor 2-positive metastatic breast cancer that 
progressed during prior trastuzumab therapy. J Clin Oncol 28(7): 1138-1144.

BASELGA J ET AL. 1996. Phase II study of weekly intravenous recombinant humanized anti-p185HER2 monoclonal antibody in patients with HER2/neu-overexpressing metastatic breast cancer. J Clin Oncol 14(3): 737-744.

BuRGESS AW, HENIS YI, HYNES NE, JOVIN T, LEVITZKI A, PINKAS-KRAMARSKI R AND YARDEN Y. 2014. EGF receptor family: twisting targets for improved cancer therapies. Growth Factors 32(2): 74-81.

CHO HS, MASON K, RAMYAR KX, STANLEY AM, GABELLI SB, DENNEY JR DW AND LEAHY DJ. 2003. Structure of the extracellular region of HER2 alone and in complex with the Herceptin Fab. Nature 421(6924): 756-760.

Chung A, CUI X, AUdeH W AND GIULIANO A. 2013. Current status of anti-human epidermal growth factor receptor 2 therapies: predicting and overcoming herceptin resistance. Clin Breast Cancer 13(4): 223-232.

CORTÉS J ET AL. 2012. Pertuzumab monotherapy after trastuzumab-based treatment and subsequent reintroduction of trastuzumab: activity and tolerability in patients with advanced human epidermal growth factor receptor 2-positive breast cancer. J Clin Oncol 30(14): 1594-1600.

ESTEVA FJ ET AL. 2002. Phase II study of weekly docetaxel and trastuzumab for patients with HER-2-overexpressing metastatic breast cancer. J Clin Oncol 20(7): 1800-1808.

Fornaro L, Lucchesi M, CAPAREllo C, VAsile E, CAPONI S, GINOCCHI L, MASI G AND FALCONE A. 2011. Anti-HER agents in gastric cancer: from bench to bedside. Nat Rev Gastroenterol Hepatol 8(7): 369-383.

FRANKLIN MC, CAREY KD, VAJDOS FF, LEAHY DJ, DE VOS AM AND SLIWKOWSKI MX. 2004. Insights into ErbB signaling from the structure of the ErbB2-pertuzumab complex. Cancer Cell 5(4): 317-328.

GALA K AND CHANDARLAPATY S. 2014. Molecular pathways: HER3 targeted therapy. Clin Cancer Res 20(6): 1410-1416.

GARNER AP ET AL. 2013. An antibody that locks HER3 in the inactive conformation inhibits tumor growth driven by HER2 or neuregulin. Cancer Res 73(19): 6024-6035.

GARRETT JT AND ARTEAGA CL. 2011. Resistance to HER2-directed antibodies and tyrosine kinase inhibitors: mechanisms and clinical implications. Cancer Biol Ther 11(9): 793-800.

GARRETT JT ET AL. 2011. Transcriptional and posttranslational up-regulation of HER3 (ErbB3) compensates for inhibition of the HER2 tyrosine kinase. Proc Natl Acad Sci USA 108(12): 5021-5026.

GHOSH R ET AL. 2011. Trastuzumab has preferential activity against breast cancers driven by HER 2 homodimers. Cancer Res 71(5): 1871-1882.

GIANNI L ET AL. 2011. Neoadjuvant pertuzumab (P) and trastuzumab $(\mathrm{H})$ : Biomarker analyses of a 4-arm randomized phase II study (NeoSphere) in patients (pts) with
HER2 positive breast cancer (BC). Cancer Res 7(Suppl 24; abstr S5-1).

GIANNI L ET AL. 2012. Efficacy and safety of neoadjuvant pertuzumab and trastuzumab in women with locally advanced, inflammatory, or early HER2-positive breast cancer (NeoSphere): a randomised multicentre, openlabel, phase 2 trial. Lancet Oncol 13(1): 25-32.

GRAUS-PORTA D, BEERLI RR, DALY JM AND HYNES NE. 1997. ErbB-2, the preferred heterodimerization partner of all ErbB receptors, is a mediator of lateral signaling. EMBO J 16(7): 1647-1655.

HARARI D AND YARDEN Y. 2000. Molecular mechanisms underlying ErbB2/HER2 action in breast cancer. Oncogene 19(53): 6102-6114.

HUANG X, GAO L, WANG S, MCMANAMAN JL, THOR AD, YANG X, ESTEVA FJ AND LIU B. 2010. Heterotrimerization of the growth factor receptors erbB2, erbB3, and insulinlike growth factor-i receptor in breast cancer cells resistant to herceptin. Cancer Res 70(3): 1204-1214.

HUDIS CA. 2007. Trastuzumab--mechanism of action and use in clinical practice. N Engl J Med 357(1): 39-51.

HYNES NE AND LANE HA. 2005. ERBB receptors and cancer: the complexity of targeted inhibitors. Nat Rev Cancer 5(5): 341-354.

JUNTTILA TT, AKITA RW, PARSONS K, FIELDS C, LEWIS PHILlips GD, FRIEDMAN LS, SAMPATH D AND SLIWKOWSKI MX. 2009. Ligand-independent HER2/ HER3/PI3K complex is disrupted by trastuzumab and is effectively inhibited by the PI3K inhibitor GDC-0941. Cancer Cell 15(5): 429-440.

Kim HH, ViJAPURKAR U, HELlyer NJ, BRAVO D AND KOLAND JG. 1998. Signal transduction by epidermal growth factor and heregulin via the kinase-deficient ErbB3 protein. Biochem J 334 (Pt 1): 189-195.

KÜMLER I, TUXEN MK AND NIELSEN DL. 2014. A systematic review of dual targeting in HER2-positive breast cancer. Cancer Treat Rev 40(2): 259-270.

KuREBAYASHI J, OtSUKI T, TANG CK, KUROSUMI M, YAMAMOTO S, TANAKA K, MOCHIZUKI M, NAKAMURA H AND SONOO H. 1999. Isolation and characterization of a new human breast cancer cell line, KPL-4, expressing the Erb B family receptors and interleukin-6. Br J Cancer 79(5-6): 707-717.

LEe-Hoeflich ST, CROCKER L, YAO E, PHAM T, MunRoE X, HOEFLICH KP, SLIWKOWSKI MX AND STERN HM. 2008. A central role for HER3 in HER2-amplified breast cancer: implications for targeted therapy. Cancer Res 68(14): 5878-5887.

LEMMON MA AND SCHLESSINGER J. 2010. Cell signaling by receptor tyrosine kinases. Cell 141(7): 1117-1134.

LI B ET AL. 2013. Bispecific antibody to ErbB2 overcomes trastuzumab resistance through comprehensive blockade 
of ErbB2 heterodimerization. Cancer Res 73(21): 64716483 .

MAMIDI S, CINCI M, HASMANN M, FEHRING V AND KIRSCHFINK M. 2013. Lipoplex mediated silencing of membrane regulators (CD46, CD55 and CD59) enhances complement-dependent anti-tumor activity of trastuzumab and pertuzumab. Mol Oncol 7(3): 580-594.

MARMOR MD, SKARIA KB AND YARDEN Y. 2004. Signal transduction and oncogenesis by ErbB/HER receptors. Int J Radiat Oncol Biol Phys 58(3): 903-913.

Mendoza N, Phillips GL, Silva J, SchWALl R AND WICKRAMASINGHE D. 2002. Inhibition of ligandmediated HER2 activation in androgen-independent prostate cancer. Cancer Res 62(19): 5485-5488.

MetzGer-Filho O, Winer EP AND Krop I 2013. Pertuzumab: optimizing HER2 blockade. Clin Cancer Res 19(20): 5552-5556.

Molina MA, CODONy-SERVAT J, AlbANEll J, Rojo F, ARRIBAS J AND BASELGA J. 2001. Trastuzumab (herceptin), a humanized anti-Her2 receptor monoclonal antibody, inhibits basal and activated Her2 ectodomain cleavage in breast cancer cells. Cancer Res 61(12): 47444749 .

Mullen P, CAMERON DA, HASMANN M, SMYTH JF AND LANGDON SP. 2007. Sensitivity to pertuzumab (2C4) in ovarian cancer models: cross-talk with estrogen receptor signaling. Mol Cancer Ther 6(1): 93-100.

NAHTA R AND ESTEVA FJ. 2006. Herceptin: mechanisms of action and resistance. Cancer Lett 232(2): 123-138.

NAHTA R, Hung MC AND ESTEVA FJ. 2004. The HER-2targeting antibodies trastuzumab and pertuzumab synergistically inhibit the survival of breast cancer cells. Cancer Res 64(7): 2343-2346.

NAHTA R, YUAN LX, ZHANG B, KOBAYASHI R AND ESTEVA FJ. 2005. Insulin-like growth factor-I receptor/human epidermal growth factor receptor 2 heterodimerization contributes to trastuzumab resistance of breast cancer cells. Cancer Res 65(23): 11118-11128.

PARK JW, NEVE RM, SZOLlosi J AND BENZ CC. 2008. Unraveling the biologic and clinical complexities of HER2. Clin Breast Cancer 8(5): 392-401.

POHL M, STRICKER I, SCHOENECK A, SCHUlmanN K, KLEIN-SCORY S, SCHWARTE-WALDHOFF I, HASMANN M, TANNAPFEL A, SCHMIEGEL W AND REINACHERSCHICK A. 2009. Antitumor activity of the HER2 dimerization inhibitor pertuzumab on human colon cancer cells in vitro and in vivo. J Cancer Res Clin Oncol 135(10): 1377-1386.

Pohlmann PR, Mayer IA AND Mernaugh R. 2009. Resistance to Trastuzumab in Breast Cancer. Clin Cancer Res15(24): 7479-7491.

REXER BN AND ARTEAGA CL. 2013. Optimal targeting of HER2-PI3K signaling in breast cancer: mechanistic insights and clinical implications. Cancer Res 73(13): 3817-3820.

RitTer CA, Perez-Torres M, Rinehart C, Guix M, DUgGer T, ENGELMAN JA AND ARTEAGA CL. 2007. Human breast cancer cells selected for resistance to trastuzumab in vivo overexpress epidermal growth factor receptor and ErbB ligands and remain dependent on the ErbB receptor network. Clin Cancer Res 13(16): 49094919.

Rosen LS, Ashurst HL AND CHAP L. 2010. Targeting signal transduction pathways in metastatic breast cancer: a comprehensive review. Oncologist 15(3): 216-235.

ROSKOSKI JR R. 2004. The ErbB/HER receptor proteintyrosine kinases and cancer. Biochem Biophys Res Commun 319(1): 1-11.

ROSS JS AND FLETCHER JA. 1998. The HER-2/neu oncogene in breast cancer: prognostic factor, predictive factor, and target for therapy. Stem Cells 16(6): 413-428.

SAKAI K, YOKOTE H, MURAKAMI-MUROFUSHI K, TAMURA T, SAIJO N AND NiSHIO K. 2007. Pertuzumab, a novel HER dimerization inhibitor, inhibits the growth of human lung cancer cells mediated by the HER3 signaling pathway. Cancer Sci 98(9): 1498-1503.

SCHEUER W, FRIESS T, BURTSCHER H, BOSSENMAIER B, ENDL J AND HASMANN M. 2009. Strongly enhanced antitumor activity of trastuzumab and pertuzumab combination treatment on HER2-positive human xenograft tumor models. 69(24): 9330-9336.

SchneEWEISS A, Chia S, HegG R, TAUsch C, DEB R, RATNAYAKE J, KIERMAIER A, MCNALLY V, ROSS G AND CORTES J. 2012. Biomarker (BM) analyses of a phase ii study of neoadjuvant pertuzumab and trastuzumab with and without anthracycline (ATC)-containing chemotherapy for treatment of HER2-positive early breast cancer (BC) (TRYPHAENA). Ann Oncol 23(Suppl 9): 83.

SCHNEEWEISS A ET AL. 2013. Pertuzumab plus trastuzumab in combination with standard neoadjuvant anthracyclinecontaining and anthracycline-free chemotherapy regimens in patients with HER2-positive early breast cancer: a randomized phase II cardiac safety study (TRYPHAENA). Ann Oncol 24(9): 2278-2284.

SERGINA NV, RAUSCH M, WANG D, BLAIR J, HANN B, SHOKAT KM AND MOASSER MM. 2007. Escape from HER-family tyrosine kinase inhibitor therapy by the kinase-inactive HER3. Nature 445(7126): 437-441.

SINGER CF, KÖSTLER WJ AND HUDELIST G. 2008. Predicting the efficacy of trastuzumab-based therapy in breast cancer: current standards and future strategies. Biochim Biophys Acta 1786(2): 105-113.

SLAMON DJ, CLARK GM, WONG SG, LEVIN WJ, ULLRICH A AND MCGUIRE WL. 1987. Human breast cancer: correlation of relapse and survival with amplification of the HER-2/neu oncogene. Science 235(4785): 177-182. 
SLAMON D ET AL. 2011. Adjuvant trastuzumab in HER2positive breast cancer. N Engl J Med 365(14): 1273-1283.

SLAMON DJ ET AL. 2001. Use of chemotherapy plus a monoclonal antibody against HER2 for metastatic breast cancer that overexpresses HER2. N Engl J Med 344(11): 783-792.

SWAIN SM ET AL. 2013. Pertuzumab, trastuzumab, and docetaxel for HER2-positive metastatic breast cancer (CLEOPATRA study): overall survival results from a randomised, double-blind, placebo-controlled, phase 3 study. Lancet Oncol 14(6): 461-471.

VADLAMUDI RK, SAHIN AA, ADAM L, WANG RA AND KUMAR R. 2003. Heregulin and HER2 signaling selectively activates c-Src phosphorylation at tyrosine 215 . FEBS Lett 543(1-3): 76-80.
VERMA S ET AL. 2012. Trastuzumab emtansine for HER2positive advanced breast cancer. N Engl J Med 367(19): 1783-1791.

VOGEL CL ET AL. 2002. Efficacy and safety of trastuzumab as a single agent in first-line treatment of HER2overexpressing metastatic breast cancer. J Clin Oncol 20(3): 719-726.

XIA W, LIU LH, Ho P AND SPECTOR NL. 2004. Truncated ErbB2 receptor (p95ErbB2) regulated by heregulin through heterodimer formation with ErbB3 yetremains sensitive to the dual EGFR/ErbB2 kinase inhibitor GW572016. Oncogene 23(3): 646-653.

YARDEN Y AND SLIWKOWSKI MX. 2001. Untangling the ErbB signalling network. Nat Rev Mol Cell Biol 2(2): 127-137. 
